\title{
A COMPARISON OF MACRO AND MiCROGEOMETRICAL PROPERTIES OF SPECIMENS MADE WiTH A FDM COMMERCIAL PRINTER AND ITS OPENSOURCE RETROFIT VERSION
}

\author{
David Piñero Vega, Moises Batista Ponce, Ana Pilar Valerga Puerta, \\ Juan Manuel Vazquez Martinez \& Severo Raul Fernandez Vidal
}
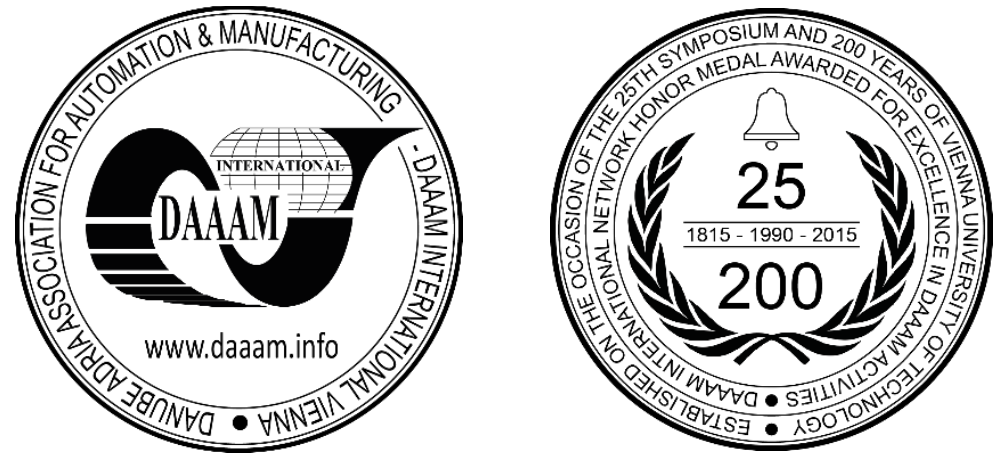

This Publication has to be referred as: Pinero Vega, D[avid]; Batista Ponce, M[oises]; Valerga Puerta, A[na] P[ilar]; Vazquez Martinez, J[uan] M[anuel] \& Fernandez Vidal, S[evero] R[aul] (2018). A Comparison of Macro and Microgeometrical Properties of Specimens Made With a FDM Commercial Printer and its Opensource Retrofit Version, Proceedings of the 29th DAAAM International Symposium, pp.1108-1115, B. Katalinic (Ed.), Published by DAAAM International, ISBN 978-3-902734-20-4, ISSN 1726-9679, Vienna, Austria

DOI: $10.2507 / 29$ th.daaam.proceedings. 158

\begin{abstract}
Fused Deposition Modeling (FDM) is one of the most used Additive Manufacturing (AM) technologies due to its low cost and easy application. FDM printer specifications are related with the quality, dimensional tolerances and geometry of manufacturing parts. FDM commercial printers with proprietary software only allow to modify a narrow range of process parameters. On the other hand, FDM opensource printers enable the user to change a wide range of manufacturing parameters and provide the possibility of edit their firmware. For this reason, a better control of FDM parameters can be performed using FDM opensource printers. In this context, the present work aims to carry out a comparison of macro and microgeometrical features of different Poly-Lactic Acid (PLA) specimens produced with a FDM commercial printer $\left(\right.$ CubeX $\left.{ }^{\circledR}\right)$ and its opensource retrofit version. Differences in printing quality of both printers have been evaluated through dimensional and geometrical measurements processes. As an outcome, FDM opensource CubeX® printer provides better quality in terms of dimensional tolerances and geometry.
\end{abstract}

Keywords: additive manufacturing; fused deposition modeling; FDM; 3D printer

\section{Introduction}

Additive Manufacturing (AM) is a group of technologies and processes that produce objects from a CAD model by adding layers of material bottom-up [1]. AM is used in the manufacturing of prototypes (Rapid Prototyping), tools (Rapid Tooling) and final functional parts (Rapid Manufacturing). These technologies provide the ability to produce complex geometries without the need of complex tooling. AM is gaining importance in the industry 4.0 due to some of its potential benefits [2]:

- Manufacturing of parts with high customization

- Great reduction in overall product development 
- On-demand manufacturing

- High potential to approach zero waste manufacturing material compared to conventional subtractive technologies

Fused Deposition Modeling (FDM) is one of the most commonly used AM technologies due to its low cost and easy application. It is an extrusion-based additive technology [3]. In FDM process, a thermoplastic filament is driven to an extruder, where is heated to a semi-liquid state by a heater block and loaded through a hotend nozzle to a printbed on X$\mathrm{Y}$ plane. The material is added layer-by-layer in $\mathrm{Z}$ axis direction. The movement commands and printing parameters are provided by a G-code file, made with a CAM or slicer program [4].

Due to the aim of promote the use of recyclable plastics in order to reduce fossil-based polymer applications, renewable thermoplastics such as Poly-Lactic Acid (PLA) are beginning to be studied because of their environmentally friendly potential and low cost. PLA is commonly used in FDM printers due to its low price $(\approx 20 € / \mathrm{kg})$, easy printing (low warping), biocompatibility (medical uses) and low melt point $(\approx 443 \mathrm{~K})$ [5].

FDM was patented by Stratasys in 1989. The expiration of the patent, in 2009, led to a growth in the interest of developing this process and several studies have been performed in recent years with the aim of improving FDM technology [6]. In this context, a community project emerged with the aim of build desktop 3D printers. This project is known as RepRap. Desktop 3D printers use FDM technology, renamed by the project as Fused Filament Fabrication (FFF) to avoid legal issues. Some parts of RepRap printers are made from thermoplastic, so these machines are selfreplicated by making kits of themselves. Additionally, these printers use opensource software and firmware. For these reasons, desktop 3D printers are low-cost and widely used among the global community [7].

Commercial printers, on the other hand, use proprietary software and normally have robust structures and enhanced mechanical and electrical components. Proprietary software only allows the user to change certain printing parameters and the rest of settings are fixed. Opensource systems, however, enable to modify a wide range of process parameters and provide the possibility of edit their firmware. For these reasons, a better control of manufacturing parameters and kinematics settings can be performed using opensource machines.

In several research and educational studies, a great combination of FDM technological settings is required to study certain effects and results. A combination of a powerful commercial printer and an opensource control system may be suitable for these studies, due to the possibility of changing most of the FDM parameters. In this context, the need of opensource FDM test benches where carrying out investigations leads the purpose of upgrading FDM printers.

In previous work, a commercial printer $\left(\mathrm{CubeX}^{\circledR}\right)$ was retrofitted and upgraded in order to improve its functionality and build an opensource machine. In this sense, the present work aims to carry out a comparison of macro and microgeometrical features of some PLA specimens produced by the original CubeX ${ }^{\circledR}$ and its opensource retrofit version, with the purpose of comparing the printing quality of both machines. The influence of the retrofit on the surface quality, geometrical accuracy and dimensional tolerances of the specimens have been evaluated through dimensional and geometrical measurements processes.

\section{Methodology}

In present work, an experimental methodology has been followed for the manufacturing and evaluation of the surface roughness (microgeometrical property), geometrical accuracy (macrogeometrical property) and dimensional tolerances of the specimens, as shown in Fig. 1.

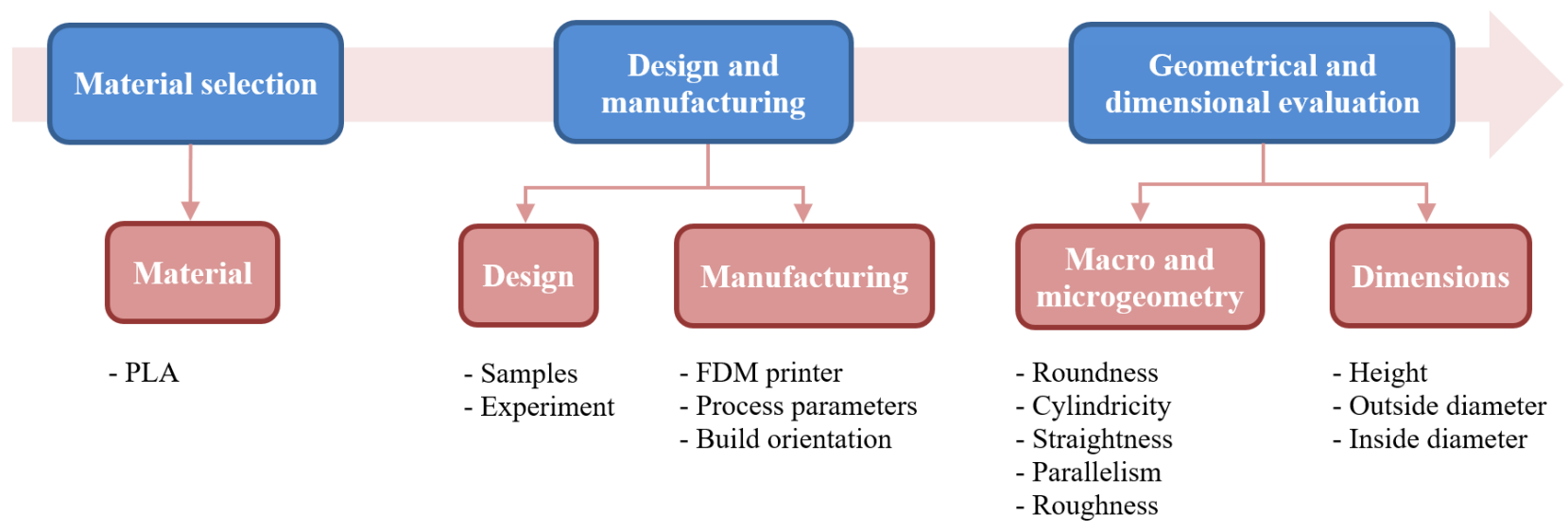

Fig. 1. Methodology for the manufacturing and evaluation of micro and macrogeometrical properties of the specimens 


\section{Experimental setup}

\subsection{Material, specimens and manufacturing}

Cylindrical specimens have been manufactured for the subsequent characterization using a commercial Cube ${ }^{\circledR}$ from 3D Systems, Inc. and its opensource retrofit version. Blue PLA filament from FFFWorld, with a nominal diameter of 1.75 $\pm 0.03 \mathrm{~mm}$, has been selected to produce the specimens. Cylinders have an outside diameter of $25 \mathrm{~mm}$, an inside hole diameter of $15 \mathrm{~mm}$ and a height of $50 \mathrm{~mm}$. Two samples have been manufactured separately with each FDM printer. The main features of both machines are listed in Table 1 .

\begin{tabular}{|c|c|c|}
\hline Feature & Commercial CubeX $^{\circledR}$ & Opensource CubeX \\
\hline Firmware & CubeX $^{\circledR}$ Firmware V1.01 & Marlin 1.1.9 (opensource) \\
\hline Hardware & CubeX $^{\circledR}$ PIC32MX440P & $\begin{array}{l}\text { Arduino Mega } 2560 \text { R3 + RAMPS } \\
1.4 \text { + } 5 \text { Allegro A4988 (opensource) }\end{array}$ \\
\hline CAM or slicer software & CubeX ${ }^{\circledR}$ Software V1.08 & Slic3r 1.3.1 (opensource) \\
\hline Extruder & $\begin{array}{c}\text { CubeX }^{\circledR} \text { extruder, } 1.75 \mathrm{~mm} \text { filament, } \\
\text { ceramic nozzle }\end{array}$ & $\begin{array}{c}\text { E3D v6, } 1.75 \text { mm filament, brass } \\
\text { nozzle }\end{array}$ \\
\hline Nozzle diameter $[\mathrm{mm}]$ & 0.5 & 0.5 \\
\hline $\mathrm{X} \& \mathrm{Y}$ belt tensor & - & Implemented \\
\hline $\mathrm{X} \& \mathrm{Y}$ resolution $[\mathrm{mm} / \mathrm{step}]$ & 0.011 & 0.011 \\
\hline $\mathrm{Z}$ resolution $[\mathrm{mm} / \mathrm{step}]$ & 0.001 & 0.001 \\
\hline
\end{tabular}

Table 1. Main features of the commercial CubeX ${ }^{\circledR}$ and its opensource retrofit version

The main selected printing parameters are shown in Table 2. Process settings have kept constant in all of the specimens. The samples have been printed directly on the printbed using a 3DLac ${ }^{\circledR}$ printing spray to avoid surface warping. The axes of the cylindrical specimens (height) were oriented in $\mathrm{Z}$ axis direction of the printers, with no build inclination, Fig.2b. Both printers were placed on a Starrett granite surface plate (Fig. 2a) in the Metrology Laboratory of the Faculty of Engineering (University of Cadiz), where environmental temperature and relative humidity are constant (298.75 K \& $60 \%$, respectively).

\begin{tabular}{cc}
\hline Printing parameter & Value \\
\hline Layer height $[\mathrm{mm}]$ & 0.25 \\
Extrusion width $[\mathrm{mm}]$ & 0.5 \\
Melting temperature $[\mathrm{K}]$ & 483.15 \\
Infill density [\%] & 100 \\
Infill pattern & Rectilinear \\
Printing speed $[\mathrm{mm} / \mathrm{s}]$ & 30 \\
Printing acceleration $\left[\mathrm{mm} / \mathrm{s}^{2}\right]$ & 1000 \\
Retraction amount $[\mathrm{mm}]$ & 2 \\
Retraction speed $[\mathrm{mm} / \mathrm{s}]$ & 40 \\
\hline
\end{tabular}

Table 2. Main selected printing parameter

\subsection{Dimensional measurement}

More than necessary measures have been done per specimen and property in order to minimize possible system errors. Standard deviation of each property average value has been obtained to assess data dispersion. In this sense, five measures of each dimension have been performed for more reliable results. This measurement process allows to detect dimensional deviations at different heights and diameters of the printed specimens.

External diameter and height were measured using two outside TESA micrometers, with ranges of $0-25$ and $50-75$ $\mathrm{mm}$. Both micrometers have resolutions of $0.01 \mathrm{~mm}$. Outside diameter was measured in five spaced sections, evenly separated along $40 \mathrm{~mm}$ of the total cylinder height by $10 \mathrm{~mm}$. Similarly, height was measured in five spaced angles, separated around the entire cylinder perimeter by $72^{\circ}$. Internal diameter was measured using an inside Mahr micrometer, with a range of $12-16 \mathrm{~mm}$ and a resolution of $0.001 \mathrm{~mm}$. Its measures were performed in the same way as the outside diameter. Dimensional measurements regions are shown in Fig. 3a. 

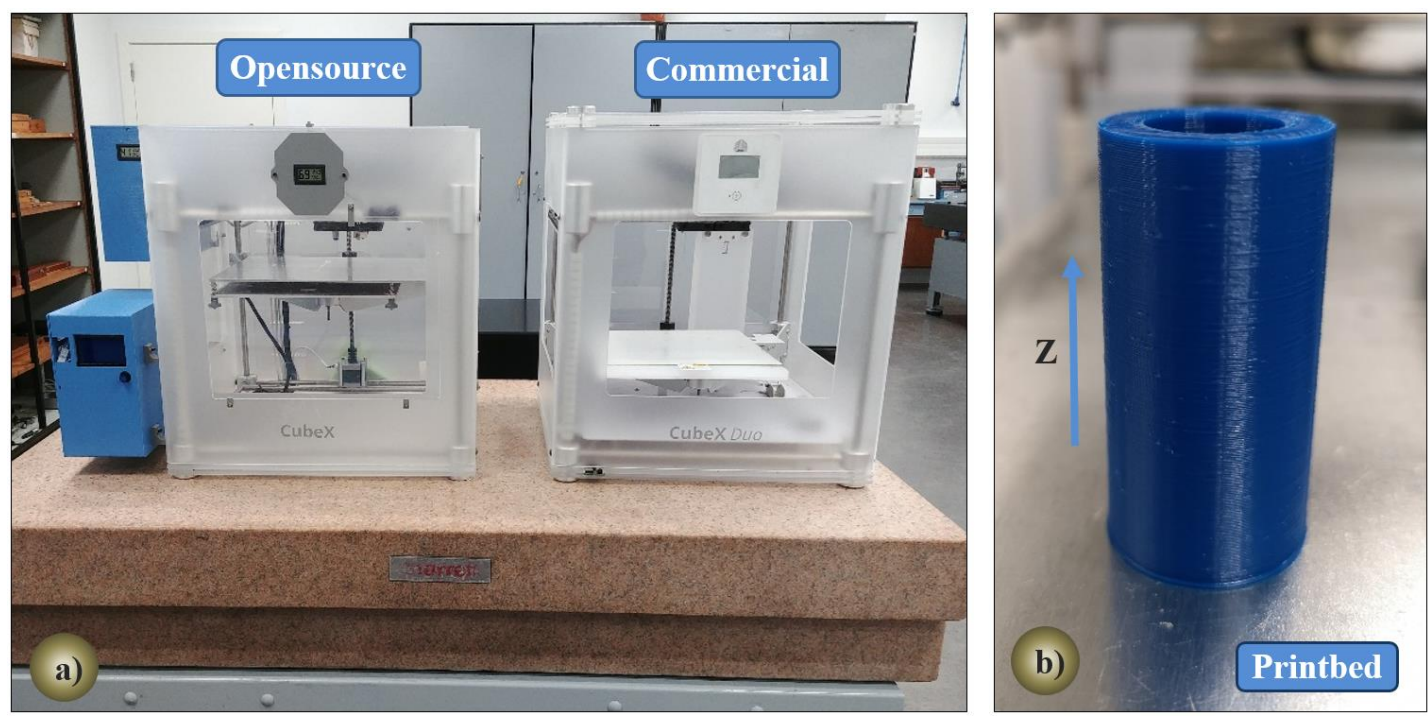

Fig. 2. a) FDM printers placed on a Starrett granite surface plate; b) Specimen orientation on the printbed

\subsection{Geometrical measurement}

Geometrical analysis of printed specimens has been divided into two different types of evaluations:

- Microgeometrical: surface roughness

- Macrogeometrical: roundness, cylindricity, straightness and parallelism

Printing parameters directly affect the surface roughness. However, process settings were kept constant in each printed sample and the used PLA filament was the same, so in this case, printer specifications and components have a greater influence on surface finish and other properties. Surface roughness was measured, in accordance with ISO 4288:1996, using a Mahr Perthometer Concept PGK 120 profilometer by performing three measurements in three spaced generatrix of the external cylinder profile, evenly separated by $120^{\circ}$. Arithmetical mean (average) roughness (Ra) and mean width of the roughness profile elements (RSm) were evaluated. Roughness measurements generatrix are shown in Fig. 3c.

Macrogeometrical deviations (circular and axial) were evaluated, according to the ISO 1101:2017, using a geometry measure machine Mahr Formtester MMQ 44. Circular deviations are composed of roundness and cylindricity measurements. Roundness was measured in five spaced sections of the outside cylinder surface, evenly separated by 10 $\mathrm{mm}$. Cylindricity was determined from roundness circular measurements. Furthermore, axial deviations are divided into straightness and parallelism. Both axial deviations were determined between the rotation axis of the cylindrical specimens and four spaced generatrix of the outside cylinder surface, evenly separated by $90^{\circ}$. Macrogeometrical measurements zones are shown in Fig. 3b.

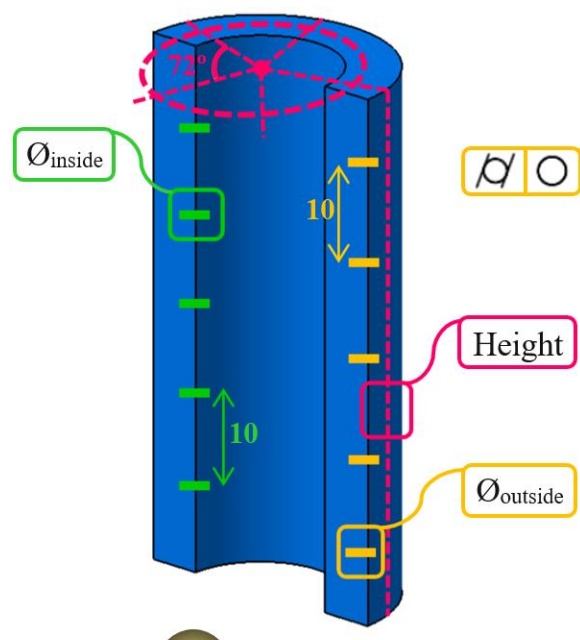

a)

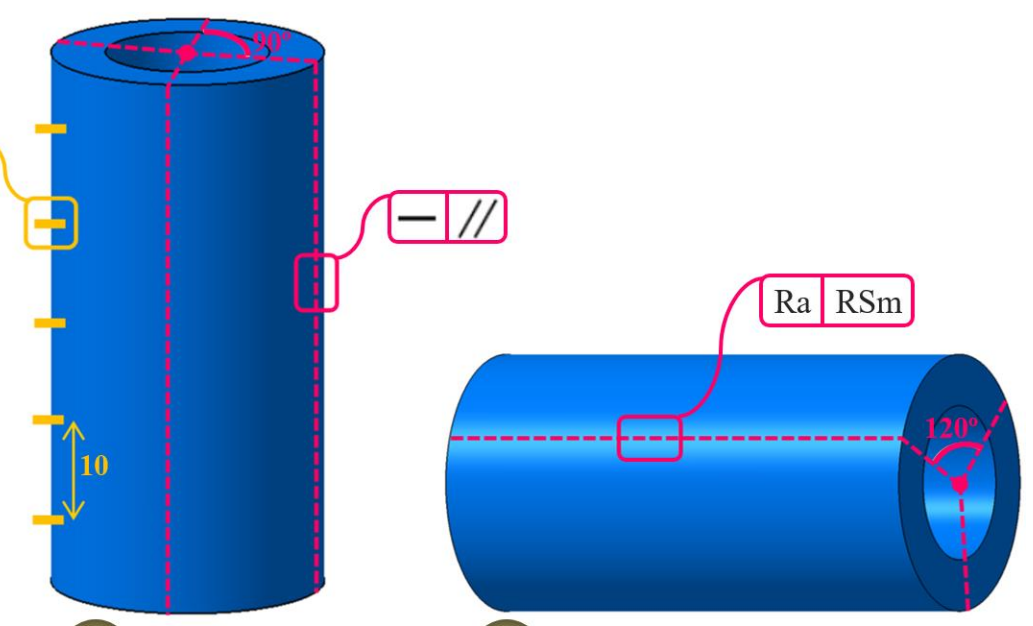

b)

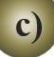

Fig. 3. a) Dimensional measurements regions; b) Macrogeometrical measurements zones; c) Roughness measurements generatrix; dimensional values are in $\mathrm{mm}$ 


\section{Results and discussion}

\subsection{Dimensional evaluation}

The outside diameter, inside diameter and height of each printed specimen have been evaluated and compared.

Both printers produced similar outside diameters, close to the nominal dimension (25 mm, red circle, Fig. 4a). Opensource cubeX $(\mathrm{O})$ provided the closest average diameter to the nominal value and brought more stable results, with lower measurement deviations. This behaviour was similar in the inside diameter evaluation (Fig. 4b). Minor dimensional accuracy of the commercial CubeX ${ }^{\circledR}$ in $\mathrm{X}-\mathrm{Y}$ plane is caused mainly by its lower tension on its $\mathrm{X} \& \mathrm{Y}$ axes belts, due to the lack of belt tensors in the original printer.

Height measurements deviations were lower in the opensource printer, which provided very accurate height dimensions close to the nominal dimension $\left(50 \mathrm{~mm}\right.$, red circle, Fig. 4c). Comercial $\mathrm{CubeX}^{\circledR}(\mathrm{C})$, on the other hand, produced height values so far from the nominal dimension. This is caused by the high die swelling generated by the original CubeX ${ }^{\circledR}$ ceramic extruder. Die swelling occurs when the melt filament leaves the print nozzle and stresses are relaxed, resulting in radial expansion of the material. The expansion generates a higher layer thickness, resulting in a greater total height [7].

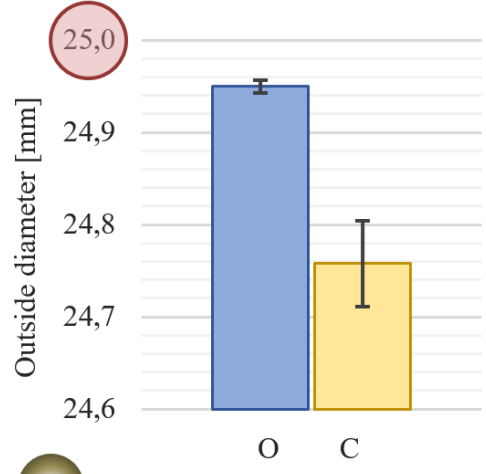

a)

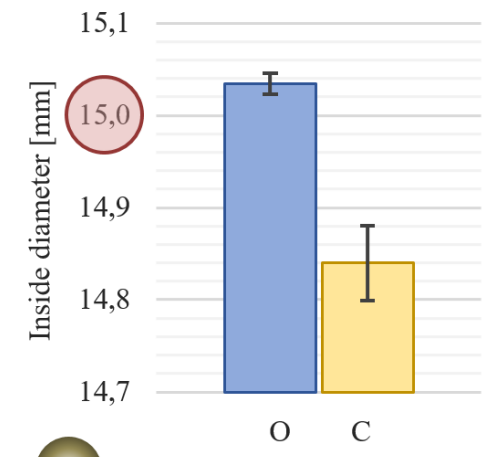

b)

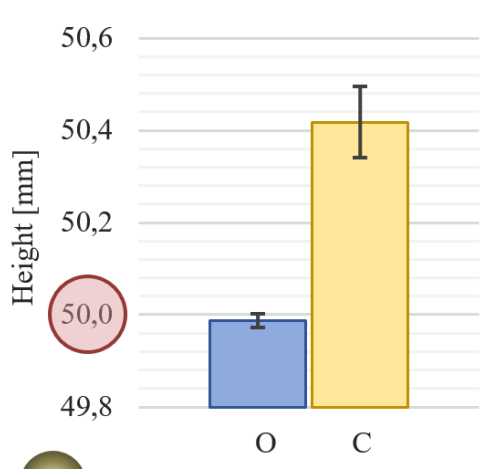

c)

Fig. 4. a) Outside diameter, b) inside diameter and c) height average values of the specimens produced by the commercial Cube $\mathrm{X}^{\circledR}(\mathrm{C})$ and its opensource retrofit version $(\mathrm{O})$

\subsection{Microgeometrical evaluation}

Ra and RSm roughness parameters of each produced specimen have been studied and compared.

Similar Ra values have been obtained with both machines (Fig 5.a). Opensource printer provided more stable results, with lower measurement deviations. A lower Ra average value (better surface finish) was achieved with the abovementioned machine. This is due to the greater number of superficial defects produced by the original printer, such as protuberances and small cavities (Fig. 6). These defects are caused mainly by the CubeX ${ }^{\circledR}$ firmware-extruder set. CubeX ${ }^{\circledR}$ firmware temperature control is not as accurate as Marlin pulse-width modulation (PWM) control, resulting in higher melting temperature variations.

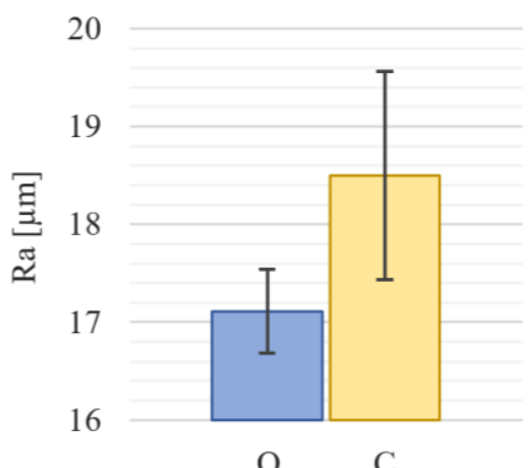

a)

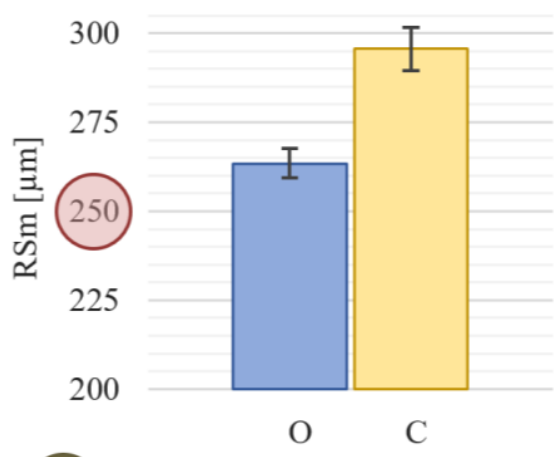

b)

Fig. 5. a) Ra and b) RSm average values of the manufactured specimens 
Original CubeX ${ }^{\circledR}$ firmware uses a temperature range of $278 \mathrm{~K}$ between the target value to control melting process. If the instant temperature is within the range, firmware does not heat the extruder until this instant temperature decrease below the minimum temperature of the range. These temperature variations are highly related with surface defects [8]. Marlin firmware heat the nozzle six times per second, and has no interval control, resulting in a more stable melting temperature.

In FDM, RSm value should be similar to the layer thickness parameter, according to its own definition. Specimens produced by the opensource CubeX provided RSm values close to the theoretical $(250 \mu \mathrm{m}$, red circle, Fig. $5 \mathrm{~b})$. Specimens manufactured by the original Cube ${ }^{\circledR}$, however, produced $\mathrm{RSm}$ average values $0.4 \mathrm{~mm}$ higher than the theoretical. This fact is caused by the high die swelling generated by the original CubeX ${ }^{\circledR}$ extruder, above-mentioned [9].

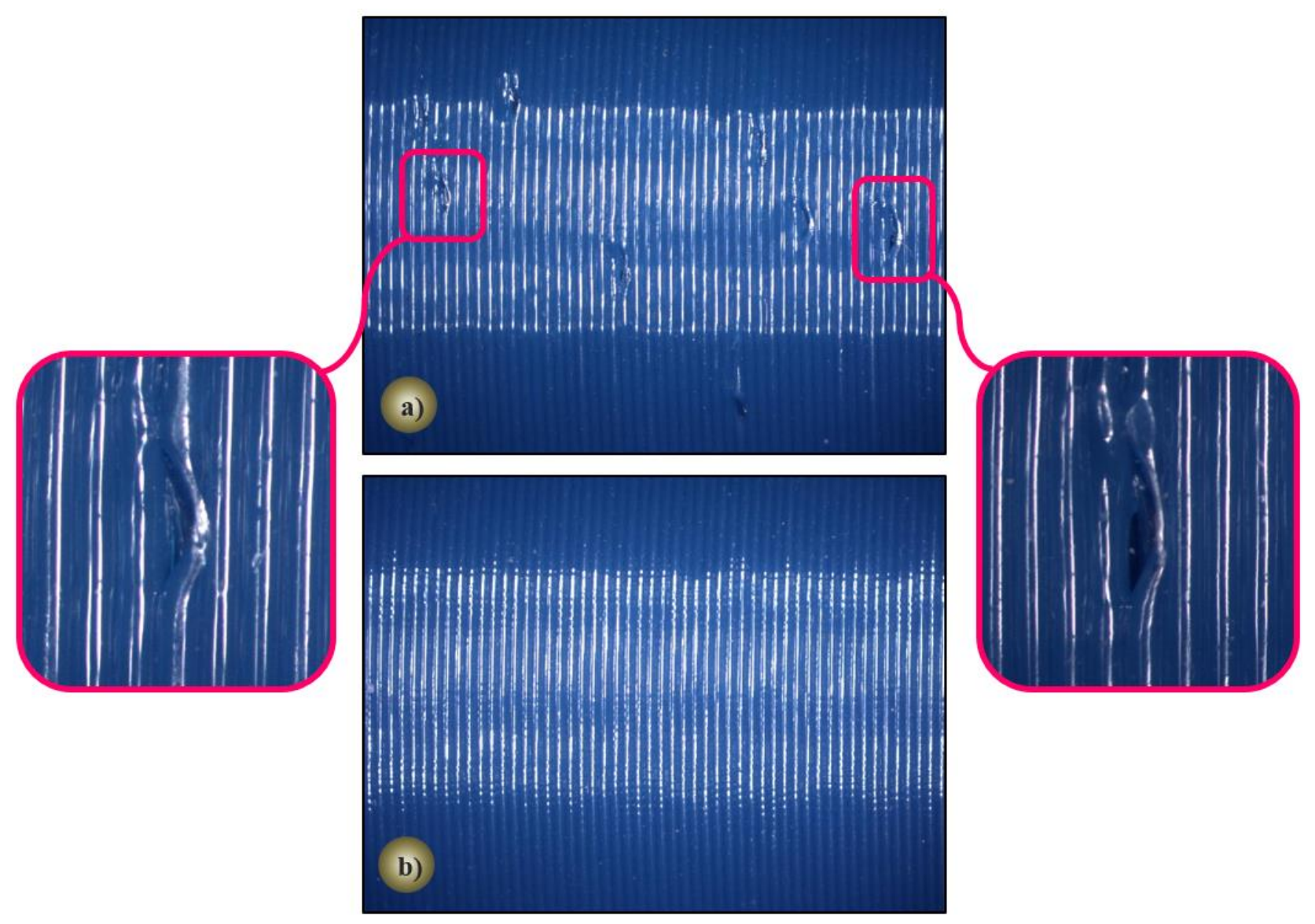

Fig. 6. a) Outside surface defects (protuberances, left; cavities, right) of one specimen manufactured by the original $\mathrm{CubeX}^{\circledR}$; b) Outside surface of one specimen produced by the opensource retrofit CubeX, with no pronounced defects

\subsection{Macrogeometrical evaluation}

Roundness, cylindricity, straightness and parallelism of each built specimen have been compared.

In general terms, opensource CubeX provided better geometrical accuracy both in macrogeometrical and microgeometrical, as shown in Fig. 7.

Printer kinematics settings are highly related with geometrical quality. In this sense, Marlin firmware and Slic3r software provide smother and accurate algorithm movements, resulting in lower geometrical deviations. In addition, implemented X \& Y belt tensors of the retrofit CubeX avoid missed steps and reduce vibrations, resulting in higher printing precision [10].

Marlin firmware has an improved movement algorithm that produces larger and smother travels than original Cube $\mathrm{X}^{\circledR}$ firmware. Short movements with numerous changes of direction generate vibrations, as occurs with commercial CubeX ${ }^{\circledR}$. In the same way, Marlin includes a function that controls the deceleration movements in corners and curves, making smother changes of direction and improving surface finish and geometrical accuracy. 


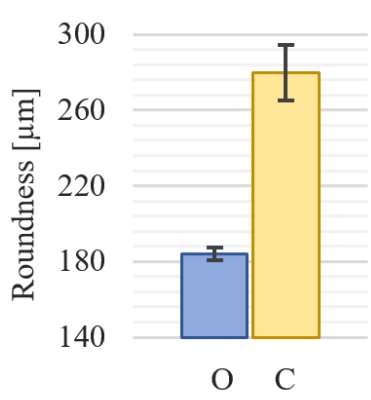

a)

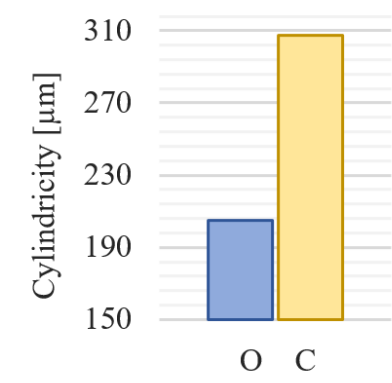

b)

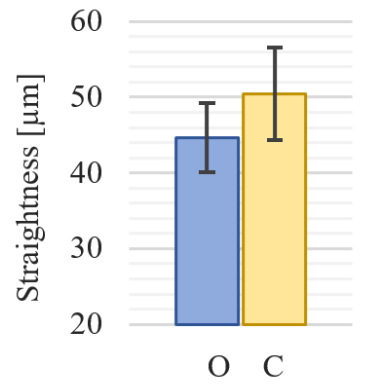

c)

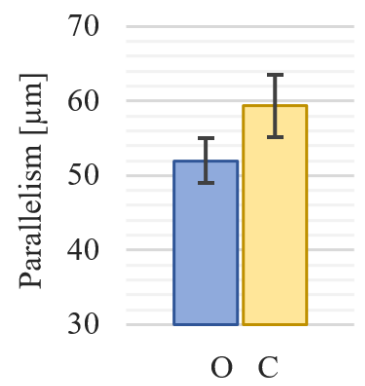

d)

Fig. 7. a) Roundness, b) cylindricity, c) straightness and d) parallelism average values of the printed specimens

\section{Conclusion}

The present work has carried out a comparison of macro and microgeometrical features of some PLA specimens produced by an original CubeX ${ }^{\circledR}$ FDM printer and its opensource retrofit version, with the aim of comparing the printing quality of both machines. A designed methodology for the manufacturing and evaluation of specimens has been followed. Two PLA cylindrical samples have been manufactured separately with each FDM machine. Dimensional and geometrical properties have been evaluated and compared.

Opensource CubeX provides better dimensional accuracy and lower deviations, due to its implemented X \&Y belt tensors and its lower die swelling effect. Outside diameter, inside diameter and height values are closer to nominal ones in the samples produced by the retrofit machine.

In the same way, surface finish is better in the specimens that were manufactured by the retrofit CubeX, due to its firmware (Marlin) and extruder (E3D v6). Marlin controls the melting temperature of the extruder by using a PWM function, resulting in a more stable temperature and a better surface quality ( $\mathrm{Ra}$ ), with less protuberances and cavities. Additionally, as mentioned above, E3D v6 extruder has less die swelling effect, so layer thickness is more accurate in the opensource printer, resulting in near to theoretical RSm values.

In terms of geometrical accuracy, opensource CubeX provided better results both in macrogeometrical and microgeometrical, due to the smother and accurate movements provided by the Marlin firmware and Slic3r software. X $\& \mathrm{Y}$ belt tensors of the retrofit CubeX avoid missed steps of stepper motors and reduce machine vibrations, resulting in higher printing quality.

This research is leading the aim of creating opensource FDM test benches, with the purpose of carrying out more studies about FDM process by studying the influence of most of the FDM parameters in the manufacturing quality. In this sense, a more ambitious and standard metrological methodology is necessary in further projects for comparing the quality between the original printers and their opensource versions, in order to prove if retrofit printers maintain or improve the quality of the printed parts.

\section{Acknowledgements}

This work has received financial support from the actions established in the Line of Action 8.1 of the II Strategic Plan of the University of Cadiz. This Plan promotes and finances the research work of the students. The authors thank the Mechanical Engineering and Industrial Design Department (DIMDI) and the Dimensional Metrology Centre for the Industry (CEMEDI), both from the Faculty of Engineering (University of Cadiz), for the provided experimental support and cooperation.

\section{References}

[1] Valerga, A.P.; Batista, M.; Fernandez Vidal, S.R.; Gomez Parra, A. \& Marcos, M. (2016). Preliminary Study of the Influence of Manufacturing Parameters in Fused Deposition Modeling, Proceedings of the 26th DAAAM International Symposium, Austria, ISSN 1726-9679, ISBN 978-3-902734-07-5, Katalinic, B. (Ed.), pp. 1004-1008, DAAAM International, Vienna, DOI: 10.2507/26th.daaam.proceedings. 141

[2] Polak, R.; Sedlacek, F. \& Raz, K. (2017). Determination of FDM Printer Settings With Regard to Geometrical Accuracy, Proceedings of the 28th DAAAM International Symposium, Austria, ISSN 1726-9679, ISBN 978-3902734-11-2, Katalinic, B. (Ed.), pp. 0561-0566, DAAAM International, Vienna, DOI: 10.2507/28th.daaam.proceedings.079

[3] Fernandez Vicente, M., Calle, W., Ferrandiz, S. \& Conejero, A. (2016). Effect of Infill Parameters on Tensile Mechanical Behavior in Desktop 3D printing, 3D Printing and Additive Manufacturing, Vol. 3, No. 3, http://dx.doi.org/10.1089/3dp.2015.0036 
[4] Bähr, F. \& Westkämper, E. (2018). Correlations between Influencing Parameters and Quality Properties of Components Produced by Fused Deposition Modeling, Procedia CIRP, Vol. 72, 2018, pp. 1214-1219

[5] Sajan, N., John, T.D., Sivadasan, M. \& Singh, N.K. (2018). An investigation on circularity error of components processed on Fused Deposition Modeling (FDM), Materials Today: Proceedings, Vol. 5, 2018, pp. 1327-1334.

[6] https://reprap.org/wiki/RepRap, (2016). RepRap Project, Accessed on: 2018-09-15

[7] Turner, B.N. \& Gold, S.A. (2015).A review of melt extrusion additive manufacturing processes: II. Materials, dimensional accuracy and surface roughness, Rapid Prototyping Journal, Vol. 21, No. 3, 2015, pp. 250-261, https://doi.org/10.1108/RPJ-02-2013-0017

[8] Valerga Puerta, A.P., Moreno Sanchez, D., Batista, M. \& Salguero, J. (2018). Criteria selection for a comparative study of functional performance of Fused Deposition Modelling and Vacuum Casting processes, Journal of Manufacturing Processes, Vol. 35, 2018, pp. 721-727

[9] Reddy, V., Flys, O., Chaparala, A., Berrimi, C.E., Amogh, V. \& Rosen, B.G. (2018). Study on surface texture of Fused Deposition Modeling, Procedia Manufacturing, Vol. 25, 2018, pp. 389-396

[10] Valerga Puerta, A.P., Batista, M., Salguero, J. \& Girot, F. (2018). Influence of PLA Filament Conditions on Characteristics of FDM Parts, Materials, Vol. 11, No. 8, 2018, pp. 1322-1335 